\title{
Iniciação científica no contexto do ensino remoto emergencial: relato de experiência de exploração dos letramentos digitais
}

\author{
Scientific initiation in the context of emergency remote teaching: report of experience of \\ exploitation of digital literatures \\ Iniciación científica en el contexto de la educación remota de emergencia: relato de experiencia de \\ explotación de letramentos digitales
}

Recebido: 05/08/2021 | Revisado: 10/08/2021 | Aceito: 16/08/2021 | Publicado: 19/08/2021

\author{
Eliza Adriana Sheuer Nantes \\ ORCID: https://orcid.org/0000-0003-3260-7264 \\ Universidade Pitágoras UNOPAR, Brasil \\ E-mail: eliza@unopar.br \\ Maria Gorett Freire Vitiello \\ ORCID: https://orcid.org/0000-0003-3838-1171 \\ Universidade Pitágoras UNOPAR, Brasil \\ E-mail: mariagorett.freirevitiello@uel.br \\ Raissa Godoy Rith \\ ORCID: https://orcid.org/0000-0001-6287-6292 \\ Universidade Pitágoras UNOPAR, Brasil \\ E-mail: raissagrith@gmail.com \\ Filipe Moreira Rodrigues \\ ORCID: https://orcid.org/0000-0001-6683-572X \\ Universidade Pitágoras UNOPAR, Brasil \\ E-mail: filipemr47@gmail.com \\ Deverson William de Oliveira \\ ORCID: https://orcid.org/0000-0002-8658-0047 \\ Universidade Pitágoras UNOPAR, Brasil \\ E-mail: deverson20170@gmail.com
}

\begin{abstract}
Resumo
Este trabalho tem como objetivo proceder um relato de experiência sobre a exploração dos letramentos digitais, em contexto de ensino remoto emergencial (ERE), apresentando a percepção dos alunos bolsistas sobre as atividades de Iniciação Científica (IC) realizadas por meio das Tecnologias Digitais de Informação e Comunicação (TDIC). A relevância da temática justifica-se na necessidade premente de alterações ocorridas na esfera educacional, devido à pandemia de COVID-19. A ancoragem epistemológica advém de teorias que discorrem sobre iniciação científica, letramentos digitais e o gênero discursivo videominuto, proposto pelo documento norteador nacional Base Nacional Comum Curricular (BNCC). A metodologia de pesquisa elegida é a qualitativa, de base empírica, advinda do relato de experiência dos alunos de IC. As categorias de análise foram "formação acadêmica e letramentos digitais". O resultado da investigação apontou para a proficuidade dos letramentos digitais na IC, no processo de ensino e aprendizagem, do aluno de graduação, visto que impactou na formação acadêmica, na esfera profissional e despertou para o prosseguimento dos estudos a nível de stricto sensu. No tocante ao contexto de pandemia, o percurso metodológico indicou que este requereu mudanças disruptivas que evocaram o domínio de letramentos digitais, alterando a práxis dos pesquisadores e indicando a necessidade de um melhor preparo dos envolvidos, mediante os múltiplos letramentos digitais requeridos na esfera digital, em um exíguo espaço de tempo.
\end{abstract}

Palavras-chave: Ensino; Iniciação científica; Letramentos digitais; Videominuto.

\begin{abstract}
This work aims to provide an experience report on the exploration of digital literacies in the context of emergency remote education (ERE), presenting the perception of scholarship students about Scientific Initiation (SI) activities carried out through Digital Information Technologies and Communication (DITC). The relevance of the theme is justified by the pressing need for changes in the educational sphere, due to the COVID-19 pandemic. The epistemological anchorage comes from theories that discuss scientific initiation, digital literacies and the videominute discursive genre, proposed by the national guiding document, National Common Curriculum Base (NCCB). The chosen research methodology is qualitative, empirically based, arising from the experience report of SI students. The analysis categories were "academic training and digital literacy". The investigation results pointed to the usefulness of digital literacies in SI in the teaching and learning process of the undergraduate student, as it impacted on academic training, in the professional sphere and awakened to the continuation of studies at the post-graduation level.
\end{abstract}


Regarding the pandemic context, the methodological path indicated that it required disruptive changes that evoked the domain of digital literacies, changing the practice of researchers and indicating the need for better preparation of those involved, through the multiple digital literacies required in the digital sphere, in a small amount of time.

Keywords: Teaching; Scientific initiation; Digital literacies; Videominute.

\section{Resumen}

Este trabajo tiene como objetivo proporcionar un relato de experiencia sobre la explotación de los letramentos digitales, en el contexto de la educación remota de emergencia (ERE), presentando la percepción de los estudiantes becarios sobre las actividades de Iniciación Científica (IC) realizadas a través de las Tecnologías Digitales de Información y Comunicación (TDIC). La relevancia del tema se justifica por la imperiosa necesidad de cambios en el ámbito educativo, debido a la pandemia de COVID-19. El anclaje epistemológico proviene de teorías que discuten la iniciación científica, los letramentos digitales y el género discursivo videominuto, propuestas por el documento brasileño para la educación Base Nacional Comum Curricular (BNCC). La metodología de investigación elegida es cualitativa, de base empírica, que surge del relato de experiencia de los estudiantes de IC. Las categorías de análisis fueron "formación académica y letramentos digitales". El resultado de la investigación apuntó a la utilidad de los letramentos digitales en IC, en el proceso de enseñanza y aprendizaje, del estudiante de grado en Letras, ya que incidió en la formación académica, en el ámbito profesional y le despertó a la continuación de estudios a nivel stricto sensu. En cuanto al contexto pandémico, la trayectoria metodológica indicó que requerió cambios disruptivos que evocaron el dominio de los letramentos digitales, cambiando la práctica de los investigadores e indicando la necesidad de una mejor preparación de los involucrados, a través de los múltiples letramentos digitales requeridos en la esfera digital, en un corto tiempo.

Palabras clave: Enseñanza; Iniciación científica; Letramentos digitales; Videominuto.

\section{Introdução}

No Brasil, desde março de 2020, a nação foi acometida pelo vírus Coronavírus da Síndrome Respiratória Aguda 2 (SARS-CoV-2), causador da COVID-19, patologia de rápido e agressivo contágio, o que requereu medidas sanitárias urgentes, dentre elas, distanciamento social, isolamento e novas formas de interação, estas propiciadas pela exploração da esfera digital, com alterações importantes no âmbito cientifico, bem como na arquitetura escola, abarcando o modo de ensino e de aprendizagem como um todo (salas de aula, participação em eventos, congressos, dentre outros).

Assim, na esfera nacional, o Conselho Nacional de Educação (CNE) emitiu o Parecer CNE/CP n. ${ }^{\circ}$ 05/2020 (Brasil, 2020), no dia 28 de abril, sendo este encaminhado ao Ministério da Educação (MEC), contendo, em seu teor, as diretrizes para o período de suspensão do ensino presencial, apontando que, durante o período de restrições sanitárias, as atividades seguem sendo aplicadas, mesmo sem a presença dos estudantes nos ambientes escolares, por meio de recursos tecnológicos ou não. Segundo o documento, essas atividades devem ser realizadas "por meios digitais (videoaulas, conteúdos organizados em plataformas virtuais de ensino e aprendizagem, redes sociais, correio eletrônico, blogs, etc.), por meio de programas televisivos ou rádio", bem como deve-se priorizar a "adoção de material didático impresso com orientações pedagógicas e pela orientação de leituras,projetos, pesquisas, atividades e exercícios indicados” (Brasil, 2020, p. 8- 9).

Diante disso, este grupo de pesquisadores, que já vem trabalhando com a Iniciação Cientifica (IC), na modalidade de ensino a distância $(\mathrm{EaD})$, deu prosseguimento às atividades acadêmicas e, neste trabalho, propõe-se a proceder um relato de experiência sobre letramentos digitais, em contexto de ensino remoto emergencial (ERE), apresentando a percepção dos alunos sobre as atividades de IC realizadas, explorando os letramentos digitais, conforme indicação da Base Nacional Comum Curricular (Brasil, 2018), doravante BNCC.

Mediante o exposto, este texto inicia-se com pressupostos epistemológicos que versam sobre a IC no Brasil, a IC na Educação a Distância $(\mathrm{EaD})$ e os letramentos digitais; a seguir, temos a metodologia de pesquisa selecionada e os relatos de três alunos bolsistas de IC, que apresentam suas percepções sobre a experiência da IC na modalidade EaD, especialmente, no tocante ao contexto do ERE. As enunciações dos referidos bolsistas foram organizadas seguindo duas categorias: formação acadêmica e letramentos digitais. 


\subsection{Iniciação Científica no Brasil: a relevância da pesquisa na formação acadêmica}

Estudos de Massi e Queiroz (2015) apresentam que a IC teve origem na década de 1930, com a criação das primeiras universidades brasileiras, e, nos de 1960, passou a ser financiada pelo Conselho Nacional de Desenvolvimento Científico e Tecnológico (CNPq). Este, por sua vez, considera a IC como etapa inicial da carreira de um cientista, de um professor e de um pesquisador, sendo um dos pilares da universidade, juntamente com o ensino e a extensão (Brasil, 2018).

De acordo com Minayo (2016), a pesquisa científica sustenta a atividade de ensino e proporciona a construção de outros saberes, como os conceituais, tecnológicos ou práticos, implicando na reorganização dos cenários sociais. Também, possibilita que os envolvidos com a pesquisa científica sejam participantes ativos do processo de construção do conhecimento, tornando-se pessoas analíticas e críticas.

Nesse sentido, em relação aos objetivos e finalidades da IC, Bridi (2015) considera que propicia o desenvolvimento da criatividade e da análise crítico-reflexiva do aluno em formação. Os estudos de Cabrero e Costa (2015) acrescentam que a IC contribui para impulsionar a formação de profissionais flexíveis, capazes de realizar trabalho individual ou em grupo, proativos, bons administradores do tempo, com capacidade de liderança e espírito colaborativo. Desse modo, cabe ressaltar que Canaan e Nogueira (2015) destacam a importância do financiamento de bolsas estudantis no processo de formação, pois propiciam a dinamicidade das experiências acadêmicas e consolidam, também, o envolvimento em eventos científicos.

Isso posto, no que diz respeito à IC, o CNPq destaca que a Constituição Brasileira de 1988 enfatiza a relevância de experiências teórico-práticas nas graduações, conforme o "princípio da indissociabilidade entre ensino, pesquisa e extensão" (Brasil, 1988). Ainda, temos na Lei de Diretrizes e Bases da Educação (LDB), Lei n. ${ }^{\circ}$ 9.346, que a IC deve estimular a criação cultural e o desenvolvimento do espírito científico e do pensamento reflexivo, e incentivar o trabalho de pesquisa e investigação científica, com a finalidade de promover o desenvolvimento da ciência e da tecnologia (BRASIL, 1996). Em 2018, a BNCC reforça a importância da IC, asseverando que a pesquisa e a divulgação científica devem ser estimuladas desde a Educação Básica, a partir de experimento científico e dos relatos multimidiáticos (Brasil, 2018).

Embora a BNCC reconheça a pesquisa científica já na Educação Básica, é no ensino superior que a IC ocupa maior espaço no cenário da educação brasileira. A pesquisa de Mazzafera e Suguimoto (2016, p. 38) verificou, em seis cursos de mestrado e doutorado, que $85,2 \%$ dos mestrandos e doutorandos participaram de programas de IC, quando estavam na graduação. Isto é, a IC é parte de um processo pedagógico e desperta disposição e interesse científico, além de ser importante fonte de produção e disseminação de conhecimentos.

\subsection{Letramentos digitais e a IC na modalidade EaD}

De acordo com Buzato (2006, p. 7), os letramentos "são práticas sociais e culturais que têm sentidos específicos e finalidades específicas dentro de um grupo social [...]". Soares (2002, p. 151) concebe o letramento digital como "certo estado ou condição que adquirem os que se apropriam da nova tecnologia digital e exercem práticas de leitura e de escrita, na tela, diferentes do estado ou condição - do letramento - dos que exercem práticas de leitura e de escrita no papel".

Os letramentos digitais possibilitam ao indivíduo a oportunidade de munir-se de diferentes ferramentas na promoção de conhecimento, o qual não necessita mais restringir-se aos métodos tradicionais de ensino, mas permite ter seu processo de ensino-aprendizagem reinventado sob novas perspectivas, em que a centralidade do ensino encontra-se pautada no aluno, e este, sendo letrado digitalmente, tem a oportunidade de compartilhar os conhecimentos alcançados, ultrapassando limites referentes à distância e ao tempo (Moran, 2015).

Vista disso, não há como desatrelar as definições que permeiam as práticas de letramento digital dos conceitos apontados no letramento, ambos visam a objetividade da linguagem como prática social em um contexto de interação, onde as habilidades desenvolvidas para a produção de significados são usadas em sua totalidade, exigindo uma nova postura frente à 
ordenação dos aspectos referentes aos processos de leitura e escrita, pois, parafraseando Buzato (2006, p. 86) "um indivíduo letrado é, consequentemente, alguém que conhece e pratica diferentes formas de falar, ler e escrever, que são construídas sócio historicamente $[\ldots] "$.

Uma vez que o conceito de letramento perpassa as barreiras do que, tradicionalmente, concebe-se como linguagem, estendendo-se para novos contextos de fala, surge uma nova definição, os "letramentos digitais", definidos por Buzato (2006, p. 16) como "práticas sociais" disponibilizadas através de meios digitais. Desse modo, a circulação do indivíduo no contexto da cibercultura exige dele a ativação de determinados conhecimentos, ou seja, uma nova perspectiva do ato de ler e interpretar se faz necessária. Nesse contexto, sobre cibercultura, cabe ressaltar:

[...] não nos cabem visões tecnofóbicas acerca da sociedade em que vivemos, mas perceber que a sociedade mediada pelas tecnologias, aqui denominadas de cibercultura, é por si só ambivalente, pois as redes trazem consigo uma série de possibilidades e fluxos que são imprescindíveis para pensar a democratização da informação. Entretanto, trazem também traços de uma semiformação ao propiciar aos indivíduos a falsa ideia de liberdade (Santos, Ferreira, \& Mello, 2019, p. 2001).

Assim, a necessidade da ampliação do conceito tradicionalmente abordado, quando trata do tema leitura e interpretação, torna igualmente necessária a ampliação de certas aptidões no contexto dos letramentos digitais, pois não basta apenas saber dominar as ferramentas tecnológicas, é preciso saber elevá-las ao patamar de instrumentos formadores de aprendizagem.

Nesse sentido, recorremos aos estudos de Dudeney, Hockly e Pegrum (2016, p. 17), que definem os letramentos digitais como "habilidades individuais e sociais necessárias para interpretar, administrar, compartilhar e criar sentido eficazmente no âmbito crescente de comunicação digital." Com isso, postula-se que as habilidades individuais e sociais utilizadas para gerar significado no contexto dos letramentos digitais requerem o uso total dos conceitos atrelados às práticas de letramento. Para tanto, os autores apresentam o Quadro 1, que contém a conceitualização dos diferentes tipos de letramento, contidos nas categorias foco na linguagem, foco na informação, foco nas conexões e foco no (re)desenho, visto serem as mais exploradas neste trabalho, para melhor contextualização, a seguir, temos o quadro completo: 
Quadro 1 - Letramentos digitais.

\begin{tabular}{|c|c|c|}
\hline \multirow{7}{*}{$\begin{array}{l}\text { Foco na } \\
\text { linguagem }\end{array}$} & $\begin{array}{l}\text { letramento } \\
\text { impresso }\end{array}$ & $\begin{array}{l}\text { Compreensão e criação da escrita on-line com seus artefatos, competências da leitura e da escrita no } \\
\text { meio digital. }\end{array}$ \\
\hline & $\begin{array}{l}\text { letramento } \\
\text { em SMS }\end{array}$ & Habilidade de usar o "internetês" com eficiência. \\
\hline & $\begin{array}{l}\text { letramento } \\
\text { em hipertexto }\end{array}$ & Habilidade de processar hiperlinks e de usá-los com eficácia. \\
\hline & $\begin{array}{l}\text { letramento } \\
\text { multimídia }\end{array}$ & Em múltiplas mídias, interpretam-se e criam-se textos. \\
\hline & $\begin{array}{l}\text { letramento } \\
\text { em jogos }\end{array}$ & $\begin{array}{l}\text { Chamado de macroletramento, porque está ligado a outro letramento, o pessoal; com interações } \\
\text { eficientes e navegações visando aos objetivos dos jogos. }\end{array}$ \\
\hline & $\begin{array}{l}\text { letramento } \\
\text { móvel }\end{array}$ & $\begin{array}{l}\text { Habilidade de comunicar-se por meio da internet móvel. Mais um macroletramento, pois se liga aos } \\
\text { letramentos em rede, em informação, em pesquisa, impresso e multimídia. }\end{array}$ \\
\hline & $\begin{array}{l}\text { letramento } \\
\text { em codificação }\end{array}$ & Permite criar canais de mídia, com habilidades de ler, escrever, criticar e modificar códigos. \\
\hline \multirow{4}{*}{$\begin{array}{l}\text { Foco na } \\
\text { informação }\end{array}$} & $\begin{array}{l}\text { letramento } \\
\text { classificatório }\end{array}$ & $\begin{array}{l}\text { Habilidade de interpretar e de criar, com eficiência, folksonomias (etiquetas, nuvens de tags, que } \\
\text { levam a listas de recursos salvos). }\end{array}$ \\
\hline & $\begin{array}{c}\text { letramento } \\
\text { em pesquisa }\end{array}$ & $\begin{array}{l}\text { Eficiência no uso dos motores de busca, com conhecimentos da funcionalidade e da limitação } \\
\text { desses serviços. }\end{array}$ \\
\hline & $\begin{array}{c}\text { letramento } \\
\text { em informação }\end{array}$ & Habilidade de criticar e de avaliar fontes de informação, verificando credibilidade e origens. \\
\hline & $\begin{array}{l}\text { letramento } \\
\text { em filtragem }\end{array}$ & $\begin{array}{l}\text { Habilidade de reduzir a sobrecarga de informação. Para isso, são importantes as redes pessoais de } \\
\text { aprendizagem confiáveis, com pessoas e recursos como fontes de apoio e de informação. }\end{array}$ \\
\hline \multirow{3}{*}{$\begin{array}{l}\text { Foco nas } \\
\text { conexões }\end{array}$} & letramento pessoal & $\begin{array}{l}\text { É um macroletramento, por necessitar do letramento impresso, em codificação e multimídia. } \\
\text { Habilidade de projetar a identidade on-line em sintonia com os seus desejos, com formatações e } \\
\text { ferramentas digitais apropriadas. }\end{array}$ \\
\hline & $\begin{array}{l}\text { letramento } \\
\text { em rede }\end{array}$ & $\begin{array}{l}\text { Habilidade de organizar redes on-line profissionais e sociais, conforme letramento em filtragem; o } \\
\text { letramento participativo - habilidade de participar com contribuições para a inteligência coletiva } \\
\text { das redes digitais. }\end{array}$ \\
\hline & $\begin{array}{l}\text { letramento } \\
\text { intercultural }\end{array}$ & $\begin{array}{l}\text { Habilidade de interagir nos diferentes contextos culturais e de interpretar documentos e artefatos } \\
\text { culturalmente diversos. }\end{array}$ \\
\hline $\begin{array}{l}\text { Foco no } \\
\text { (re)desenho }\end{array}$ & $\begin{array}{l}\text { letramento } \\
\text { remix }\end{array}$ & Habilidade de criar mixagens nas redes digitais, fazendo-as circular com seus novos sentidos. \\
\hline
\end{tabular}

Fonte: adaptado de Dudeney, Hockly e Pegrum (2016, p. 17-18)

Alguns dos letramentos citados no quadro já foram levados a campo, por ocasião da pesquisa realizada, por meio da dissertação de Mestrado intitulada Iniciação Científica na modalidade da Educação a Distância: a mediação por meio de ferramentas digitais, na qual Vitiello (2019) apresenta a pesquisa realizada com alunos de um curso de graduação/licenciatura na modalidade $\mathrm{EaD}$, em que foram exploradas as TDIC, como ferramentas mediadoras no processo de IC, sendo elas apresentadas na figura que segue, a qual evidencia as conexões dos diferentes dispositivos e recursos utilizados por meio do AVA, do smartphone, das conexões via e-mail e do recurso Google Forms. 
Figura 1 - Ferramentas mediadoras para orientação de IC.

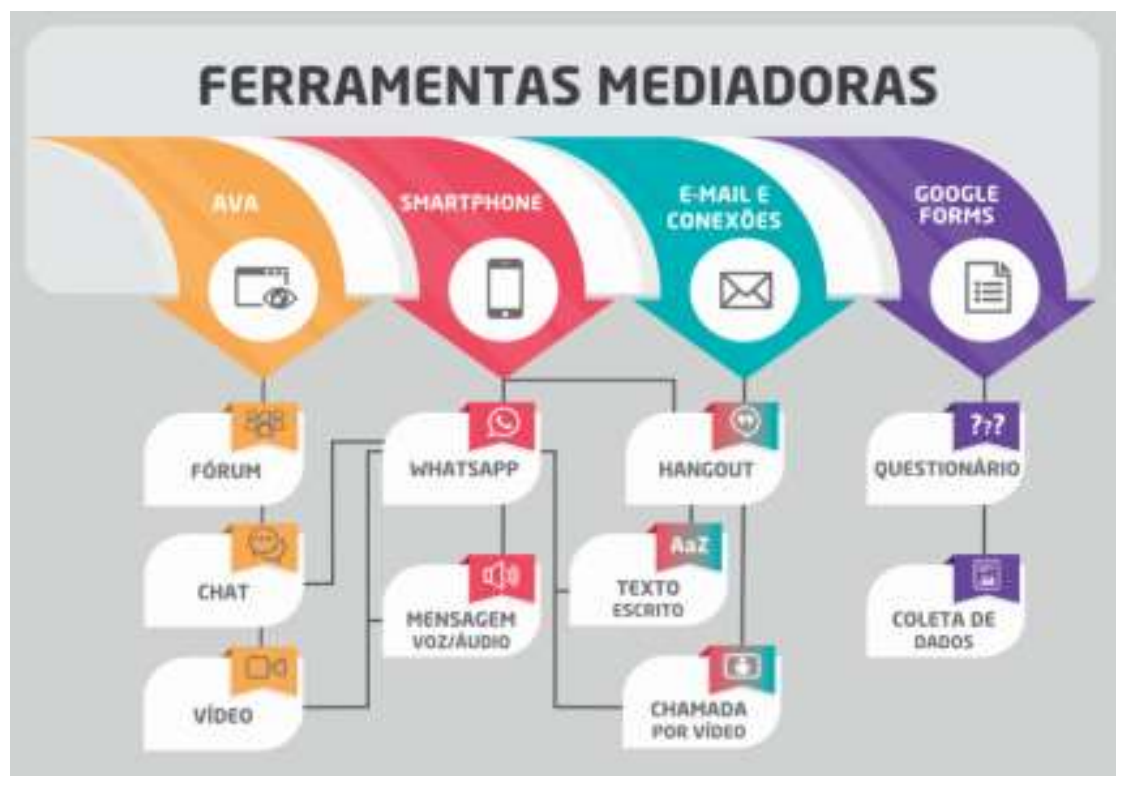

Fonte: Vitiello (2019, p. 79).

Isso posto, ancorado na referida pesquisa, este artigo traz o relato de experiência de exploração de algumas dessas ferramentas, realizada por estes autores, que, durante o ERE, fizeram uso de tais recursos, permitindo, dessa forma, que as atividades de IC tivessem prosseguimento, mesmo em contexto pandêmico, conforme veremos na discussão e análise dos dados, dispostos na sequência da metodologia usada.

\section{Metodologia}

Como já apresentado na introdução, a metodologia de pesquisa selecionada converge com o objetivo deste trabalho, que é proceder um relato de experiência sobre a exploração dos letramentos digitais, em contexto de ERE, apresentando a percepção dos alunos sobre as atividades de IC realizadas. Assim, ancorados nos pressupostos epistemológicos de Paiva (2019), este estudo caracteriza-se como uma pesquisa de base empírica, pois não prevê a aplicabilidade de um saber visando a resolução de uma problemática.

Trata-se, ainda, de um relato de experiência, logo, o gênero relato de experiência "é uma atividade social cuja nomenclatura depende da abordagem teórica", sendo que "a Literatura o classifica sob a categoria dos gêneros narrativos e a Linguística classifica-o sob a categoria de relatos de experiência pessoal" (Carvalho, 2011, p. 53).

Por fim, é uma pesquisa que se pauta na experiências dos autores, restrito às ações que envolvem a percepção dos alunos de IC sobre seu percurso acadêmico e como agenciaram os letramentos digitais, em contexto do ERE; sendo, ainda, uma pesquisa primária, visto os dados apresentados emergirem do relato dos próprios pesquisadores, o que nos conduz a ser uma pesquisa qualitativa, apresentando a descrição das experiências individuais, registradas por meio da realização de uma das atividade aplicadas na IC, especificamente, sobre o uso de TDIC no gênero videominuto.

Os dados das análises constituem-se de relatos dos participantes, também autores deste trabalho, cujas experiências são aqui descritas. São questões, portanto, que resultam de suas percepções acerca de vivências experienciadas em seu contexto de formação pedagógica. Esses participantes são caracterizados a partir das informações elencadas no Quadro 2, o qual nos indica serem bolsistas, inseridos na área de ensino, vinculados à graduação, na modalidade EaD. O quadro apresenta a fonte de fomento pagadora das bolsas de estudo desses alunos, as respectivas áreas de formação, bem como a cidade e o Estado em que residem esses bolsistas. 
Quadro 2 - Caracterização dos participantes.

\begin{tabular}{|c|l|l|l|}
\hline Participante & Bolsista & Formação & Local geográfico \\
\hline A1 & CNPq & Letras-EaD & Giruá - RS. \\
\hline A2 & Funadesp & Letras-EaD & $\begin{array}{l}\text { Lagoa da Prata-MG. Mudou, durante a } \\
\text { pandemia, para Porto Alegre - RS } \\
\text { (atual). }\end{array}$ \\
\hline A3 & Funadesp & Enfermagem-EaD & Rolândia-PR. \\
\hline
\end{tabular}

Fonte: Autores (2021).

Assim, os corpora para a atividade geradora dos dados são a transcrição das enunciações desses alunos bolsistas, oriundas da produção realizada por eles, do gênero da esfera digital, videominuto, indicado pela BNCC (Brasil, 2018, p. 509), documento norteador da educação brasileira que indica serem desenvolvidas com os alunos habilidades, dentre elas, citamos: "(EM13LP17) Elaborar roteiros para a produção de vídeos variados vlog, videoclipe, videominuto, documentário etc.", a fim de "ampliar as possibilidades de produção de sentidos e engajar-se em práticas autorais e coletivas". A diretriz para a produção do vídeo teve como proposta o aluno apresentar uma reflexão sobre a IC em seu processo de formação acadêmica.

Para a produção, foi indicado um estudo realizado por este grupo de pesquisadores, o qual já havia sistematizado e caracterizado o gênero videominuto, trabalho já apresentado no $11^{\circ}$ Seminário de Iniciação Científica e Tecnólogica e $2^{\circ}$ Seminário de Pesquisa e Pós-graduação Stricto Sensu, (Rodrigues, Rith, \& Nantes, 2020). Antes de transcrevermos o videominuto, este foi produzido conforme os critérios apresentados no quadro 3, que busca chamar atenção para o que deve ser considerado ao se trabalhar com o videominuto em suas diferentes perspectivas.

Quadro 3 - Roteiro videominuto

\begin{tabular}{|c|c|c|}
\hline Autor & Perspectiva & O analista deve considerar: \\
\hline BNCC (2018) & Tempo & $\begin{array}{l}1 \text { minuto ou o que for solicitado. } \\
\text { Ensaiar e fazer as adequações do texto ao tempo. }\end{array}$ \\
\hline Rojo (2012) & Celular & Celular, computador ou outro dispositivo que o aluno tenha para gravação. \\
\hline $\begin{array}{l}\text { Gerbase (2012); } \\
\text { Penafria (2009) }\end{array}$ & Local & Iluminação adequada, local silencioso, roupa básica e acessórios moderados. \\
\hline Bakhtin (2010) & Finalidade & Objetivo e contexto claros. \\
\hline $\begin{array}{l}\text { Gerbase (2012); } \\
\text { Penafria (2009) }\end{array}$ & $\begin{array}{l}\text { Planos } \\
\text { e } \\
\text { ângulos }\end{array}$ & $\begin{array}{l}\text { Plano: frontal. } \\
\text { Ângulo: frontal. } \\
\text { Duração: plano-sequência. }\end{array}$ \\
\hline $\begin{array}{l}\text { Bakhtin (2010); } \\
\text { Penafria (2009 }\end{array}$ & Roteiro escrito & $\begin{array}{l}\text { Organizar um texto em forma de itens. } \\
\text { Seleção lexical: excertos responsáveis pela produção de sentidos do texto. } \\
\text { Abertura: apresentação de quem está falando e o objetivo. } \\
\text { Progressão temática: ater-se ao objeto estudado. } \\
\text { Práticas sociais: atrelar o objeto estudado ao mundo do trabalho. } \\
\text { Fechamento: encerrar. }\end{array}$ \\
\hline $\begin{array}{l}\text { Bakhtin (2010); } \\
\text { Rojo (2012); } \\
\text { Bortoni-Ricardo } \\
\quad(2005)\end{array}$ & $\begin{array}{l}\text { Multimodalidade na } \\
\text { oralidade }\end{array}$ & $\begin{array}{l}\text { Explorar a dialogicidade e a persuasão: personalização da imagem, gestos, ritmo, } \\
\text { entonação, pausas, hesitações, repetições, riso, olhar, movimentos corporais, volume } \\
\text { da voz, adequação da fala, perguntas retóricas. }\end{array}$ \\
\hline
\end{tabular}

Fonte: Rodrigues et al. (2020). 
Mediante o exposto, na análise do texto, serão considerados, dentro das categorias elegidas, os aspectos: finalidade, texto com abertura, objetivo, progressão temática, fechamento e, como se trata do gênero discursivo videominuto, adequação ao tempo. Assim, prosseguindo, após a gravação do videominuto produzido pelos alunos e a transcrição dos excertos, os dados foram sistematizados e categorizados à luz da teoria dos gêneros discursivos oriunda dos estudos de Bakhtin (2010) e seus caudatários, visto que o objeto de análise origina-se da transcriação do gênero produzido pelos alunos: o gênero discursivo videominuto. Assim, elegemos a categoria "conteúdo temático", sendo selecionados temas afins, devidamente agrupados por similaridade de sentidos semânticos, encontradas na análise dos sentidos via seleção lexical. Mediante o exposto, delimitamos no Quadro 4, as categorias de análise e seus aspectos constituintes, conforme segue:

Quadro 4 - Categorias de análise.

\begin{tabular}{|c|c|}
\hline Categoria & Aspecto constituinte \\
\hline Formação acadêmica & Impacto na formação acadêmica. \\
\hline Letramentos Digitais & Letramentos Digitais desenvolvidos. \\
\hline
\end{tabular}

Fonte: Autores (2021).

Tendo delimitado as categorias, passemos à discussão e à análise dos excertos transcritos, a partir da atividade videominuto. Na sequência, abordaremos os excertos das transcrições feitas a partir dessa atividade.

\section{Resultados e Discussão}

Para a discussão e a análise dos dados, organizamos essa seção, apresentando a transcrição dos dizeres do videominuto de cada participante e, dentro das proposições, procederemos a leitura à luz das categorias já apresentadas: formação acadêmica e letramentos digitais. Iniciemos com os excertos de A1, aluna do sétimo período de Letras:

Olá! Eu me chamo Al, sou aluna do sétimo período de Letras da Universidade " $X$ " e, também, aluna de iniciação científica, pelo terceiro ano. Bem, considerando o contexto de pandemia, as metodologias ativas nos proporcionaram um novo diálogo com os meios de comunicação. Dessa forma, houve a necessidade de reaprendermos, em muito pouco tempo, como nos comunicar por novos contextos digitais, através de recursos como reuniões via Google Meet, Microsoft Teams, fazer vídeos, editar, fazer cursos no AVA e o WhatsApp que me permitiu uma maior aproximação com a professora e os colegas de pesquisa. Isso despertou a vontade de prosseguir com o mestrado. Assim, pode-se dizer que as metodologias ativas se tornam deveras eficazes quando tratamos do tema "Ensino e educação", pois elas nos permitiram estreitar as distâncias e, também, a participação em simpósios, encontros e seminários que, se não fosse por meio dos aparatos tecnológicos, nós não teríamos como comparecer.

No contexto pandêmico, dificuldades e incertezas se instauraram nas instituições de ensino e "requereram urgência na solução dos conflitos, poder de decisão, redimensionamento de práticas e a construção de um novo fazer pedagógico" (Temóteo, 2021, p. 74). Essa afirmativa pode-se perceber também na percepção e na compreensão dos alunos, no que diz respeito às adequações para o acompanhamento das aulas e atividades acadêmicas nesse período.

Com relação à categoria "Letramentos digitais", A1 expressa em suas proposições que “[...] considerando o contexto de pandemia, as metodologias ativas nos proporcionaram um novo diálogo com os meios de comunicação [...] houve a necessidade de reaprendermos, em muito pouco tempo, como nos comunicar por novos contextos digitais". Pode-se perceber que houve, também para o aluno, a necessidade de reaprender, em pouco tempo, como comunicar-se nesse contexto de pandemia, que exigiu sobremaneira o uso de recursos digitais. Desse modo, é fato que tais exigências evidenciaram, igualmente, a necessidade crucial do letramento digital, tanto para professores quanto para os alunos. Isso porque, para além de 
permitir a comunicação, esse modo de intervir, via metodologias ativas, propiciou a aproximação necessária entre alunos e professores, para a continuidade das atividades educacionais, que se deu por meio do ERE.

Já, sob o viés da categoria "Formação acadêmica", de acordo com A1, a facilitação de acesso aos conteúdos e atividades acadêmicas promovida com o uso de recursos digitais, tais como, "reuniões via Google Meet, Microsoft Teams, fazer vídeos, editar, fazer cursos no AVA e o WhatsApp", no contexto pandêmico, "[...] permitiu uma maior aproximação com a professora e os colegas de pesquisa". Isso propiciou, segundo A1, "[...] a participação em simpósios, encontros e seminários que, se não fosse por meio dos aparatos tecnológicos", e essa compreensão segue com a afirmativa de que, sem tais recursos, "nós não teríamos como comparecer". As enunciações de A1 expressam a compreensão de que, por meio das tecnologias, especificamente, quanto às metodologias ativas, pode-se, na contemporaneidade, principalmente, em um momento que requer reformulações no modo de comunicação entre professores e alunos devido ao contexto pandêmico, realizar ações educacionais que propiciem a interação e permitam a aproximação entre alunos e professores, mesmo que estejam separados geograficamente (Moran, 2013). Igualmente, que a aluna, ao realizar o uso de tais recursos, tem certa familiaridade e acessibilidade às TDIC, bem como adquiriu novos saberes por meio destes.

No entanto, cabe ressaltar que essa aproximação possível por meio das TDIC se dá de forma significativa quando, nesse contexto, há a presença, ainda que de modo virtual/remoto, do professor. É o professor o elo da mediação pedagógica, profissional apto a propiciar a transformação necessária para que possam, juntos (professor e aluno), trilhar caminhos para essa interação e apreensão de novos saberes: não basta a existência dos recursos tecnológicos para a efetividade da comunicação. É necessário compreender a realidade e ter subsídios teóricos que possam sustentar e conduzir para a mudança necessária de hábitos e de ações, de modo a promover e/ou amenizar os problemas detectados e vivenciados pelos alunos.

Com o suporte das metodologias ativas, o professor pode propiciar, para além da interação, a possibilidade de o aluno identificar as problemáticas que envolvem o contexto vivenciado nesse momento pandêmico, bem como a resolução dos problemas e dificuldades quando auxiliados entre os pares. Isso significa dizer que a autonomia do aluno não se resume ao agir sozinho, especialmente, nesse contexto de pandemia, em meio a mudanças tanto no modo de realizar as ações educacionais, quanto no próprio comportamento (que requer distanciamento e afastamento social), tendo ainda que lidar com as diferentes realidades familiares, o que abala e modifica a dinâmica de estudo. Essa condição faz que o aluno considere e saiba como e com quem contar no processo de formação. Também, onde buscar informações e orientações capazes de ampará-lo nas diferentes situações em que se encontrar no processo de formação.

Nesse sentido, deve-se atentar para "a necessidade de facilitação da acessibilidade a esses ambientes virtuais de aprendizagem", visando, assim, propiciar "a inclusão social e a integração, na interface de diferentes contextos que promovam processos de ensino e de aprendizagem socialmente relevantes" (Temóteo, 2021, p. 73).

Somente com a segurança, no tocante a esse amparo nesse processo, é que se pode motivar o aluno para a continuidade dos estudos. Uma vez amparado e orientado para a condução, o sucesso e a superação de suas dificuldades, podese despertar no aluno o desejo para a continuidade no processo de formação, pois, conforme expressado nas enunciações de A1, que, mais uma vez, ancora-se na categoria "Formação acadêmica", "despertou a vontade de prosseguir com o mestrado".

Outro fator relevante diz respeito à afirmativa nas proposições de A1 ao expressar que: "pode-se dizer que as metodologias ativas se tornam deveras eficazes quando tratamos do tema 'Ensino e educação’, pois elas nos permitiram estreitar as distâncias". Essa asserção permite aferir que o aluno da IC na modalidade $\mathrm{EaD}$, por meio das metodologias ativas, pôde experienciar recursos digitais, os quais lhe garantiu o amparo e o respaldo necessário no processo.

Contudo, há que se considerar as reais condições do aluno, do professor e da instituição de ensino. Identificar as peculiaridades de cada um é importante, visto que, ao trabalharmos, na educação, com as TDIC aplicadas às metodologias ativas, pode-se ter, de fato, o estreitamento de distâncias e a aproximação necessária para a efetividade do ensino e da 
aprendizagem, desde que haja condições de acesso e de acessibilidade que permitam essa aproximação. Isso envolve infraestrutura e capacitação pedagógica, o que requer a compreensão de que, para a obtenção de uma educação de qualidade, devem-se reconhecer as diferenças regionais, bem como as habilidades dos envolvidos no processo de formação.

Portanto, deve-se ter o cuidado ao afirmar essa aproximação, em um contexto generalizante, considerando as especificidades do aluno, do ambiente de formação e as peculiaridades de cada região, instituição e, até mesmo, condições econômica e social do aluno, por vezes, até mesmo do professor, pois certamente irão refletir na capacidade de letramento digital de ambos.

Dando seguimento, temos na sequência excertos de A2, aluno de IC do sétimo período de Letras.

Olá, meu nome é A2, sou aluno de IC, há quatro anos, entrei no primeiro ano de faculdade e estou no sétimo período de Letras. A tecnologia abrange o acesso incluindo todos, mesmo morando distante. Eu sou exemplo desta inclusão. Não sabia nada de pesquisa e graças à tecnologia eu pude ter orientação e participar, mesmo morando em uma cidade longe. Participei de eventos, simpósios, encontros de lives, bancas de seminários, EAC e tive que melhorar a escrita. Tudo isso com os recursos tecnológicos como WhatsApp, e-mail, Microsoft Teams, Google Meet, dentre outros. Esse ano exigiu muito letramento digital, passou a ser fundamental. Participar da IC foi fundamental para eu conseguir minha vaga no meu trabalho atual, concorri com 89 pessoas, ficaram 12, depois fiquei em segundo lugar e consegui ser chamado, pois já estava acostumado a falar em público, devido aos eventos, acho que me ajudou muito.

Com o reordenamento das atividades acadêmicas devido ao rompimento da presencialidade de professores e alunos nos espaços educacionais, houve a urgência de pôr em prática metodologias que permitissem ao educador propor novas formas de interatividade no ensino. A necessidade de deixar de lado as formas tradicionais de interação para a realização das atividades acadêmicas (e de todas as demais instâncias educacionais) acionou outros mecanismos que envolveram o uso de recursos digitais para a proposição e a efetividade do andamento das ações educativas, mobilizando esforços de toda a comunidade acadêmica/educacional, que passou a contar com o ERE - trabalho remoto e estudos pela modalidade EaD. Sobre isso, Santos, Ribeiro e Fernandes (2021, p. 25) esclarecem:

Saímos do modus operandi que conhecíamos para o acionamento de algo "desconhecido" [...] Daí uma grande necessidade de entendimento do que seria ensino remoto, educação a distância e ensino híbrido, definidos respectivamente como ensino emergencial acionado em contexto de pandemia. O remoto utiliza-se de mediação tecnológica para ir ao encontro do aluno em formato síncrono; a EAD, por sua vez, se constitui em uma modalidade de ensino com legislação e currículo próprio com predominância de formato assíncrono, [...] o ensino híbrido ou blended learning, por sua vez, consiste em mesclar as modalidades on-line e presencial.

Essa reorganização e ajustes na metodologia de ensino, visando o atendimento das demandas educacionais, bem como a mediação via tecnologias digitais para a continuidade das atividades de ensino tornaram possível, por meio do ERE, incluir o aluno na vivência acadêmica, no contexto de pandemia.

Referenciando a categoria "Letramentos digitais", o aluno A2 propõe que "A tecnologia abrange o acesso incluindo todos, mesmo morando distante. Eu sou exemplo desta inclusão. Não sabia nada de pesquisa e graças à tecnologia eu pude ter orientação e participar, mesmo morando em uma cidade longe". Desse modo, temos, nas enunciações de A2, o reconhecimento de que, com o uso das TDIC, pode-se mediar, instruir e propiciar a inclusão do aluno que possui acessibilidade e acesso às mídias. Isso significa dizer que as políticas educacionais devem prover meios, a fim de a acessibilidade ser do alcance de todos e, efetivamente, propiciar a democratização do acesso à internet, visando a inclusão dos alunos nos diferentes espaços de formação e saberes. Essa assertiva consta ainda no fragmento a seguir, o qual volta-se para o viés da categoria "Formação Acadêmica": "Participei de eventos, simpósios, encontros de lives, bancas de seminários, EAC e tive que melhorar a escrita. Tudo isso com os recursos tecnológicos como WhatsApp, e-mail, Microsoft Teams, Google Meet, dentre outros". 
Sobre o enunciado, dentre os diferentes recursos digitais que promovem a interação entre alunos e professores, bem como o acesso aos espaços da rede e ao ERE, estudos de Santos et al. (2021, p. 25) apontam que "as lives foram dispositivos acionados com muita potência formativa para proporcionar diálogos formativos no contexto da pandemia”, propiciando a discussão de diferentes temáticas, meio pelo qual "as universidades mantiveram uma dinâmica de interação com todos os segmentos acadêmicos". No que tange à definição de lives, são "transmissões síncronas, em tempo real, de conteúdo em forma de vídeo on-line, que se materializam por meio de diferentes metodologias" (Santos, 2020 apud Santos et al., 2021, p. 25).

Nesse sentido, "o digital em rede, caracterizado pela rede mundial de computadores, ao permitir que estejamos simultaneamente em diferentes espaços físicos compartilhando sentidos, potencializa e democratiza o conhecimento" que, por intermédio da ciberpresencialidade atinge maior público maior de modo síncrono e assíncrono, pois "os vídeos das lives ficam disponibilizados nas plataformas e transitam entre os praticantes culturais" (Santos et al., 2021, p. 26).

De acordo com a perspectiva apresentada nos excertos de A2, este ancora-se na categoria "Formação Acadêmica". É importante ressaltar que, para o acesso e a inclusão nesses espaços de formação, é necessário, também, conhecimento dos espaços e de como utilizá-los, o que requer letramento digital dos envolvidos. Essa necessidade foi também percebida pelos alunos, conforme destaca A2, ao expressar que "Esse ano exigiu muito letramento digital, passou a ser fundamental". Nessa perspectiva, cabe dizer que trabalhar com a IC, seja na modalidade presencial ou na EaD, requer, dos atores envolvidos, letramento digital para a alfabetização científica, visto que a pesquisa orientada desempenha função salutar no processo de ampliação das ideias e na formação de pesquisadores. Essa compreensão é importante pois permitirá que o aluno exercite o senso crítico e possa perceber a importância da IC na formação acadêmica, o que foi experienciado e aferido por A2 ao dizer que: "Participar da IC foi fundamental para eu conseguir minha vaga no meu trabalho atual [...] consegui ser chamado, pois já estava acostumado a falar em público, devido aos eventos, acho que me ajudou muito".

As colocações de A2, ancoradas na formação acadêmica, propiciam a reflexão e a necessária percepção de que novos tempos exigem novas ações e métodos de ensino que possam incluir diferentes possibilidades de ensinar e aprender. Conforme Santos et al. (2021), devemos considerar:

[...] as necessidades formativas que foram emergindo em contexto de pandemia, nos provocaram, nos ensinaram a buscar caminhos outros no pensar/saber/fazer formação docente, privilegiando a oportunidade de uma relação com o conhecimento formativo referenciado nas demandas e nos sentidos de um aprender plural, dialógico e, principalmente, experiencial. Nesse aspecto, encontramos, em Ribeiro (2015), uma problematização sobre o ser professor no ensino superior no contexto da cibercultura, trazendo a importância em significarmos os processos formativos pelos/nos quais nos tornamos professores, ou seja, onde, como e em que tempo se forma o professor universitário? (Santos et al., 2021, p. 26)

Assim, pode-se afirmar que as ferramentas e recursos digitais são importantes, mas deve-se considerar o papel fundamental do professor, de mediador dessa transformação, bem como a possibilidade de uma formação que propicie, cada vez mais, maior desempenho e capacitação do professor e do aluno, no sentido de incluí-los nos espaços e tempos da era digital.

Dando continuidade às análises, segue excerto referente às colocações de A3, aluno IC há 1 ano:

Eu sou A3, aluno de iniciação científica faz 1 ano. Considerando, então, o ensino remoto emergencial, a sala de aula foi ampliada e, desta forma, ganhou um espaço digital, um AVA enriquecedor, tendo como centralizador os letramentos digitais. $O$ ensino remoto foi capaz de democratizar o meu acesso a eventos (simpósios, orientações, congressos) o qual eu não poderia ter participado antes, o que contribuiu de forma bastante significativa na minha formação, pois tudo era novo para mim, muita informação nova, ampliando os meus conhecimentos e ainda contribuindo para enriquecimento do meu currículo, deixando-me mais próximo da orientadora de IC, com o grupo do WhatsApp, tanto que, devido a participação na IC, pretendo fazer o mestrado. 
Nas proposições de A3, percebe-se a imersão na categoria "Letramentos digitais": "Considerando, então, o ensino remoto emergencial, a sala de aula foi ampliada e, desta forma, ganhou um espaço digital, um AVA enriquecedor, tendo como centralizador os letramentos digitais". Constata-se que é possível a IC na modalidade EaD e, segundo as asserções do aluno, é possível afirmar que o uso das TDIC como ferramentas mediadoras no processo de formação foi profícuo e promove o letramento digital do discente.

Por sua vez, conforme a perspectiva da categoria "Formação acadêmica", nos dizeres de A3, "o ensino remoto foi capaz de democratizar o meu acesso a eventos (simpósios, orientações, congressos) o qual eu não poderia ter participado antes, o que contribuiu de forma bastante significativa na minha formação". Assim, os recursos tecnológicos podem ser explorados como ferramenta mediadora, pois propiciam, ao aluno da modalidade $\mathrm{EaD}$, nesse contexto de ERE, o acesso à pesquisa. Nesse sentido, sobre a IC, o estudo de Vitiello (2019) ressalta que é importante propiciar tal experiência aos alunos, pois, por meio da pesquisa, o conhecimento científico se efetiva e permite a compreensão dos contextos e da realidade social. A prática da pesquisa associada ao ensino proporciona ao aluno uma formação diferenciada, pois envolve os sujeitos no processo de construção do conhecimento, despertando o senso crítico. Nessa perspectiva, Vitiello (2019) pontua, ainda, que, para a proficuidade da IC durante a graduação, é fundamental haver investimento de recursos e políticas voltadas à educação, o que envolve pensar, no contexto pandêmico, a disponibilização de recursos para acessibilidade às redes e, também, que os agentes envolvidos no cenário educacional estejam empenhados para a concretização desse projeto.

Em se tratando do uso das TDIC, especialmente, quanto ao melhor uso dos recursos, é evidente a necessidade de conhecimento e apropriação de letramento digital, pois, conforme afirmativa de A3, a qual ancora-se na categoria "Formação acadêmica": "tudo era novo para mim, muita informação nova, ampliando os meus conhecimentos e ainda contribuindo para enriquecimento do meu currículo, deixando-me mais próximo da orientadora de IC, com o grupo do WhatsApp”. Isso demonstra a percepção do aluno quanto ao aprendizado adquirido e a reflexão sobre a importância da manutenção das atividades de IC para a formação com qualidade e respeito às necessidades discentes, o que exige a observância das especificidades e proposição de ações com metodologias ativas, a fim de inseri-los no contexto vivenciado. Nesse momento em que alunos e professores se encontram em diferentes espaços físicos e em territórios distintos, ou seja, geograficamente separados, é necessário estarem virtualmente juntos (Moran, 2013, p. 30). Para tanto, faz-se necessário uma formação alicerçada pelas TDIC.

Nessa perspectiva, no que diz respeito ao uso de recursos como o WhatsApp, Vitiello (2019, p. 148) pontua que o aplicativo é um facilitador nesse processo de interação via remota, pois possibilita "maior adesão dos sujeitos envolvidos, motivando o processo interacional, bem como a eficácia na solução de dúvidas e na condução das atividades".

Já nesta pesquisa, o que se destacou, pelas proposições dos participantes, quanto aos Letramentos Digitais, pode ser sintetizada na imagem que segue. Nela pode-se observar os diferentes recursos e ferramentas que compõem a síntese das categorias "letramentos digitais": 


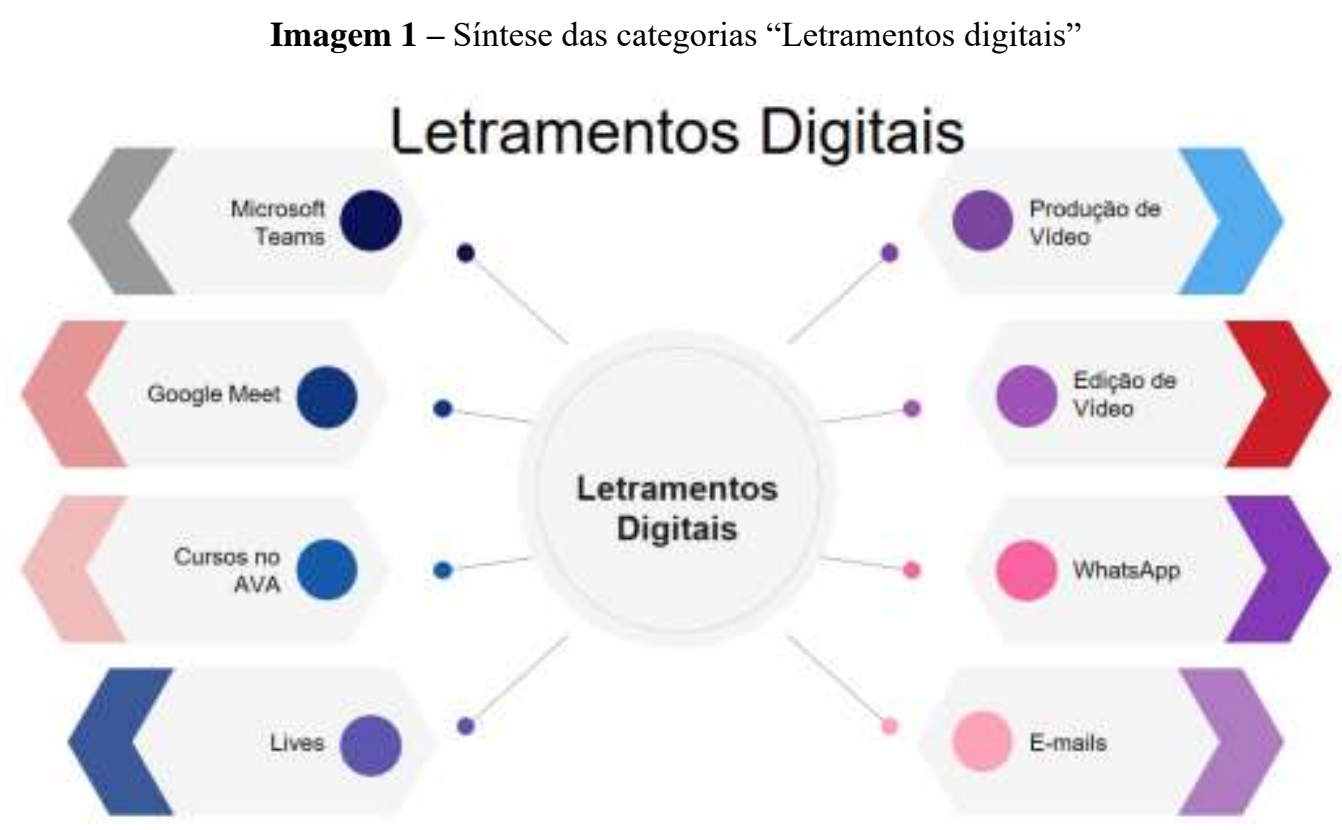

Fonte: Autores (2021).

Isso posto, a análise das respostas coletadas por meio dos excertos da atividade videominuto apontou que, no ERE, o uso das TDIC bem como o letramento digital, em especial para a IC na modalidade EaD, são necessários e profícuos, pois, quando apreendidos pelos sujeitos envolvidos no processo, potencializam as atividades de pesquisa nessa modalidade. Essa compreensão é fundamental, especialmente em relação à formação docente, pois “[...] os praticantes culturais desenvolveram letramentos digitais ao operar com plataformas e interfaces digitais e suas diversas linguagens, e também os multiletramentos críticos". Possibilita, portanto, que os alunos de IC reflitam "ao se reconhecerem como protagonistas que contestam suas próprias práticas e que anunciam novos sentidos a elas, percebendo que, na docência on-line, é possível atuar juntamente com seus estudantes como produtores, construtores e transformadores de conhecimentos, das relações entre si e com os outros e das práticas educativas". (Santos et al., 2021, p. 32).

Enfim, se imbricarmos as duas categorias elencadas, as proposições dos participantes podem ser sintetizadas na imagem a seguir, em que se destacam as palavras que remetem ao uso das TDIC, especialmente no que diz respeito a apreensão de letramentos digitais na formação:

Imagem 2 - Imbricamento das categorias "Formação acadêmica e "Letramentos digitais".

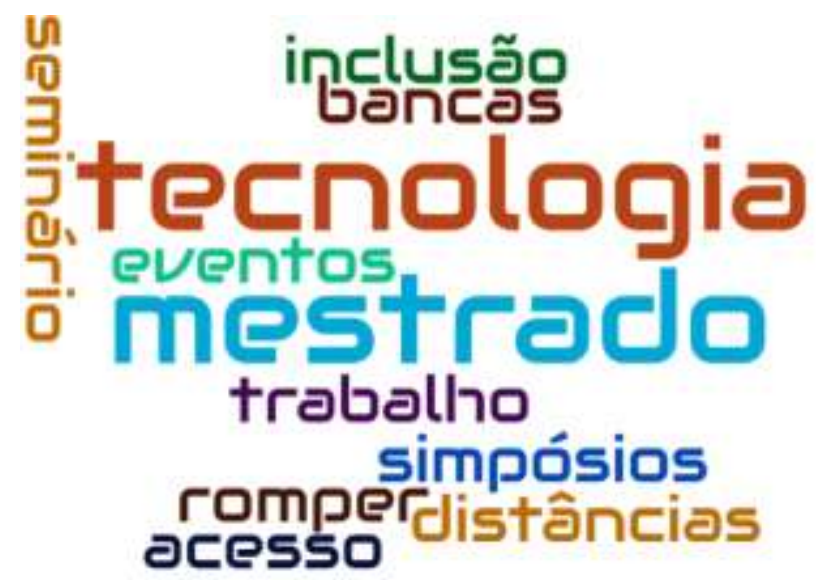

Fonte: Autores (2021). 
A leitura da imagem nos permite asseverar que a questão da IC na formação dos alunos, tanto com relação ao impacto na formação acadêmica, como nos Letramentos Digitais desenvolvidos, trouxe um avanço considerável, visto haver o predomínio da tecnologia enquanto uma ferramenta para romper a distância geográfica, possibilitando mediações necessárias para a inclusão digital, e para a orientação do alunos de IC à participação em eventos, seminários, simpósios e bancas, nos quais disseminaram suas pesquisas. Contudo, dois itens nos chamaram a atenção: o despertar para o prosseguimento dos estudos, a nível de stricto sensu, via Mestrado e, ainda, a IC ter propiciado saberes que auxiliaram na inserção do aluno no mundo do trabalho.

\section{Considerações Finais}

Iniciamos o percurso a fim de proceder um relato de experiência letramentos digitais, em contexto de ERE, apresentando a percepção dos alunos sobre as atividades de iniciação científica explorando os letramentos digitais. Para tanto, fomos ouvir a voz dos pesquisadores de IC, a fim de mapearmos o impacto da IC na formação acadêmica e os letramentos digitais requeridos.

No tocante ao contexto de pandemia, diante do novo cenário educacional, o percurso metodológico indicou alterações disruptivas, as quais requereram o domínio de letramentos digitais, alterando a práxis dos pesquisadores, apontando ser preciso um melhor preparo dos envolvidos, mediante os múltiplos letramentos digitais requeridos na esfera digital. Os alunos não haviam sido preparados, em contexto anteriores, para os múltiplos letramentos requeridos no contexto pandêmico, o que foi considerada uma mudança disruptiva, ocorrida em um curto espaço de tempo, aspecto que deve ser considerado, pois fatores como acesso a equipamentos, conexão e conhecimento foram alguns dos percalços enfrentados por todo o grupo de pesquisadores.

Assim, retomando as categorias elencadas, na "Formação acadêmica", os dados apontam que a IC fortaleceu aspectos como a democratização do saber, uma vez que propiciou aos alunos a participação em eventos, deixando de lado as formas tradicionais de comunicação, provendo a imersão, efetiva, na multimodalidade e na esfera digital, e requerendo novas e plurilinguagens; e maior proximidade com orientadora, pesquisadores e demais membros do grupo de pesquisa, ao estreitar distâncias, fortalecer os laços e ampliar a dialogicidade e os saberes.

No que diz respeito à categoria "Letramentos digitais", o impacto fez-se presente na ampliação do espaço de sala de aula, pois, através da introdução das tecnologias digitais nesse cenário, ao mesmo tempo em que as distâncias foram encurtadas, a expansão do saber mostrou-se significativa, dessa forma, por meio de recursos como Google Meet, Microsoft Teams, produção de vídeos, editores de vídeos, lives, e-mail e WhatsApp. Muito daquilo que, antes, centrava-se apenas em um contexto presencial expandiu-se para um ensino dinâmico e eficiente.

Enfim, o resultado desta investigação apontou para a proficuidade e a efetividade da IC no processo de formação do aluno de graduação, visto que o impactou na formação acadêmica, na esfera profissional, bem como o instigou a prosseguir seus estudos, a nível de stricto sensu.

Mediante o exposto, no prosseguimento das ações, este grupo se debruçará na aplicabilidade dos gêneros midiáticos, mais especificamente o videominuto, junto aos diferentes níveis de ensino, desde a educação básica, como também vincularemos as ações dos pesquisadores do stricto sensu, pois muitos são professores que atuam na educação básica. Para a socialização das pesquisas, já temos eventos que participamos anualmente, dentre eles destacamos o Encontro de Atividades Científicas da Unopar Pitágoras, que este ano está na $24^{\mathrm{a}}$ edição. Justificamos a seleção deste evento por ser de abrangência nacional, online, gratuito, possibilita trabalhos em grupo o que nos permite socializar as pesquisas realizadas, ademais trata-se de um espaço de encontro entre alunos de Iniciação Científica Júnior, Iniciação Científica, na modalidade de graduandos, professores da educação básica, alunos da pós-graduação e pesquisadores. 


\section{Agradecimentos}

À FUNADESP - Fundação Nacional de Desenvolvimento do Ensino Superior Particular, a CAPES - Coordenação de Aperfeiçoamento de Pessoal de Nível Superior e ao CNPq - Conselho Nacional de Desenvolvimento Científico e Tecnológico, pelo apoio financeiro destinado à pesquisa.

\section{Referências}

Bakhtin, M. (2010). Estética da criação verbal. Trad. Maria Ermantina Galvão G. Pereira. Martins Fontes.

Brasil. (2018). Base Nacional comum curricular. http://basenacionalcomum.mec.gov.br/wp-content/uploads/2018/02/bncc-20dez-site.pdf.

Brasil. (1988). Constituição (1988). Constituição da República Federativa do Brasil. Senado Federal: Centro Gráfico.

Brasil. (2017). Decreto . $^{\circ}$ 9.057, de 25 de maio de 2017. Regulamenta o art. 80 da Lei n. ${ }^{\circ} 9.394$, de 20 de dezembro de 1996 , que estabelece as diretrizes e bases da educação nacional. Diário Oficial da União.

Brasil. (1996). Lei de Diretrizes e Bases da Educação Nacional - Lei n. ${ }^{\circ}$ 9.394, de 20 de dezembro de 1996. Diário Oficial [da] República Federativa do Brasil. www.planalto.gov.br/ccivil_03/LEIS/19394.htm.

Brasil. Conselho Nacional de Educação. (2020). Parecer CNE/CP n. ${ }^{\circ}$ 05/2020, de 28 de abril de 2020. Reorganização do Calendário Escolar e da possibilidade de cômputo de atividades não presenciais [...] em razão da Pandemia da COVID-19. encurtador.com.br/lFGKR.

Bridi, J. C. A. (2015). A pesquisa nas universidades brasileiras: implicações e perspectivas. In: Massi, Luciana, Queiroz, Salete Linhares (Orgs). Iniciação científica: aspectos históricos, organizacionais e formativos da atividade no ensino superior brasileiro. Unesp. p. 13-35.

Buzato, M. E. K. (2006). Letramentos digitais e formação de professores. III Congresso Ibero-Americano EducaRede: Educação, Internet e Oportunidades, São Paulo. www.researchgate.net/publication/242229367_Letramentos_Digitais_e_Formacao_de_Professores.

Cabrero, R. de C., Costa, M. da P. R. da. (2015). Iniciação científica, bolsa de iniciação científica e grupos de pesquisa. In: Massi, Luciana, Queiroz, Salete Linhares (Orgs.). Iniciação científica: aspectos históricos, organizacionais e formativos da atividade no ensino superior brasileiro. Unesp. p. $109-129$.

Canaan, M. G., \& Nogueira, M. A. (2015). Bens em disputa no campo universitário: o efeito de fatores socioeconômicos e culturais no acesso à bolsa de iniciação científica. In: Massi, Luciana, Queiroz, Salete Linhares (Orgs). Iniciação científica: aspectos históricos, organizacionais e formativos da atividade no ensino superior brasileiro. Unesp. p. 65-85.

Carvalho, M. J. L. (2011). Gênero relato de experiência: um olhar sobre as estratégias cognitivas e discursivas em aquisição de linguagem. Dissertação, Universidade Federal da Paraíba, João Pessoa. https://repositorio.ufpb.br/jspui/handle/tede/6363?locale=pt_BR.

Dudeney, G., Hockly, N., \& Pegrum, M. (2016). Letramentos Digitais. Trad. Marcos Marcionilo. Parábola Editorial.

Massi, L., Queiroz, S. L. (2015). A perspectiva brasileira da iniciação científica: desenvolvimento e abrangência dos programas nacionais e pesquisas acadêmicas sobre a temática. In: Massi, Luciana, Queiroz, Salete Linhares (Orgs.). Iniciação científica: aspectos históricos, organizacionais e formativos da atividade no ensino superior brasileiro. Unesp. p. 37-64.

Mazzafera, B. L., \& Suguimoto, H. H. (2016). Programa de Iniciação Cientifica: influência no aumento quantitativo e qualitativo da produção científica. Política e Gestão Educacional (Online), 20, 38-48. https://periodicos.fclar.unesp.br/rpge/article/view/9391.

Minayo, M. C. de S. (2016). Pesquisa social: teoria, método e criatividade. Vozes.

Moran, J. M. (2015). Educação híbrida: um conceito-chave para a educação. In: Bacich, L., Tanzi Neto, A., Trevisani, F. M. (Orgs.). Ensino híbrido: personalização e tecnologia na educação. Penso. 27-46.

Paiva, V. L M de Oe. (2019). Manual de pesquisa em estudos linguísticos. Parábola.

Rodrigues, F. M, Rith, R. G., \& Nantes, E. A. S. (2020). Iniciação Científica: a exploração dos Letramentos Digitais na formação do aluno. $11^{\circ}$ Seminário De Iniciação Científica E Tecnológica / $2^{o}$ Seminário De Pesquisa E Pós-Graduação Stricto Sensu, 1-9. https://repositorio.pgsskroton.com//handle/123456789/33032.

Santos, A. R. de J., Ferreira, D. C. R. R., \& Mello, E. de. (2019). Ainda a semiformação: contribuições de Adorno e Horkheimer em tempos de cibercultura. RIAEE - Revista Ibero-Americana de Estudos em Educação, Araraquara, 14 (4), 1993-2002.

Soares, M. (2002). Novas práticas de leitura e escrita: letramento na cibercultura. Educação \& Sociedade, Campinas, 23(81), 143-160. www.scielo.br/pdf/es/v23n81/13935.pdf.

Vitiello, M G. F. (2019). Iniciação Científica na Modalidade da Educação a Distância: a Mediação por meio de Ferramentas Digitais. Dissertação, Universidade Norte do Paraná, Londrina. https://repositorio.pgsskroton.com//handle/123456789/30151.

Santos, E., Ribeiro, M., \& Fernandes, T. (2021). Ciberformação docente em contexto de pandemia: multiletramentos críticos em potência. In: Kersch, Dorotea Frank, Martins, Ana Patricia Sá, Santos, Gabriela Krause dos, Temóteo, Antônia Sueli S. G. (Orgs). Multiletramentos na pandemia aprendizagens na, para a e além da Escola [recurso eletrônico]. Ed. Casa Leiria. p. 23-36.

Temóteo, A. S. S. G. (2021). A constituição de letramentos, durante a pandemia: desafios para professores e alunos. In: Kersch, D. F., Martins, A. P. S., Santos, G. K. dos, Temóteo, A. S. S. G. (Orgs). Multiletramentos na pandemia aprendizagens na, para a e além da Escola [recurso eletrônico]. Ed. Casa Leiria. p. $69-84$. 